THE FEBRUARY REVOLUTION OF 1917

\title{
AND LAND PROPERTY OF THE RUSSIAN MONARCH: NATION-WIDE DIMENSION AND REGIONAL FACTOR ${ }^{1}$
}

\author{
Pavel A. Afanasyev \\ Altai State Pedagogical University, Barnaul, Russian Federation \\ Evgeniya V. Demchik \\ Altai State University, Barnaul, Russian Federation
}

\begin{abstract}
The article deals with the poorly studied issue on the land property of Nicholas II after his renunciation of throne. The primary attention of historians to political elimination of autocracy sets the purpose to study motives, factors and events associated with the elimination of emperor's land tenure in Russia. By the beginning of 1917 the lands included the Altai and the Nerchinsk districts under the Cabinet of his Emperial Majesty. Cabinet's land tenure was considered to be personal property of the emperor. The authors show that for the first days of work the Provisional government hadn't designated accurately its attitude to the land property of the overthrown emperor. Only on March 7 the Minister of Agriculture was entrusted to establish an order of management and use of the Cabinet's lands. The pressure upon the Provisional government was conditioned by the tense situation developing during the February revolution in the Altai district, the largest possession of the emperor. After overthrow of autocracy the population of the region had initiated mass unauthorized capture of the woods, removal of local officials of the Cabinet in response to former tough policy of the Cabinet. Therefore new local authorities demanded the fastest solution of the question of Cabinet's land tenure from Provisional government. Pressure from the region had influenced the choice of radical fate of Cabinet's land tenure by the government. Lands and incomes of the Cabinet had been announced to be the property of the state. But the resolution of Provisional government turned to be ill-considered. It didn't explain the legal bases of this transfer, the order of use of lands for the population of the region. In the Altai district the resolution of Provisional government led to disorder of a uniform complex of the Cabinet's land. Elimination of the Cabinet property in the region had only strengthened resistance of local officials of the Cabinet and radical moods of the population concerning the former property of the emperor.

E. V. Demchik analyzed the activities of the Provisional government on the question of land property of the overthrown emperor. P. A. Afanasyev revealed the regional context of the problem and the importance of the adopted government decisions.

Key words: February revolution, Cabinet of his emperor majesty, Provisional government, Cabinet's land tenure, Altai district.

Citation. Afanasyev P.A., Demchik E.V. The February Revolution of 1917 and Land Property of the Russian Monarch: Nation-Wide Dimension and Regional Factor. Vestnik Volgogradskogo gosudarstvennogo universiteta. Serija 4, Istorija. Regionovedenie. Mezhdunarodnye otnoshenija [Science Journal of Volgograd State University. History. Area Studies. International Relations], 2017, vol. 22, no. 6, pp. 77-86.(in Russian). DOI: https://doi.org/10.15688/jvolsu4.2017.6.8

\section{ФЕВРАЛЬСКАЯ РЕВОЛЮЦИЯ 1917 ГОДА И ЗЕМЕЛЬНАЯ СОБСТВЕННОСТЬ РОССИЙСКОГО МОНАРХА: ОБЩЕГОСУДАРСТВЕННОЕ ИЗМЕРЕНИЕ И РЕГИОНАЛЬНЫЙ ФАКТОР ${ }^{1}$}

\author{
Павел Алексеевич Афанасьев
}

Алтайский государственный педагогический университет, г. Барнаул, Российская Федерация 


\section{Евгения Валентиновна Демчик}

Алтайский государственный университет, г. Барнаул, Российская Федерация

Аннотация. В статье рассматривается малоизученный вопрос о мотивах, факторах и событийной стороне ликвидации императорского землевладения в России. К началу 1917 г. оно было представлено Алтайским и Нерчинским округами под управлением Кабинета Его Императорского Величества. Кабинетское землевладение считалось личной собственностью императора. Авторы показывают, что в первые дни работы Временное правительство не обозначило четко своей позиции в отношении земельной собственности свергнутого императора. Только 7 марта министру земледелия было поручено установить порядок заведования и использования земель Кабинета. Давление на Временное правительство оказала напряженная ситуация, складывавшаяся в ходе Февральской революции в Алтайском округе, крупнейшем владении императора. После падения самодержавия население региона в ответ на прежнюю жесткую политику Кабинета начало массовый самовольный захват лесов, смещение местных чиновников Кабинета. Поэтому новые органы местной власти потребовали от Временного правительства скорейшего решения вопроса о кабинетском землевладении. Давление со стороны региона повлияло на принятие правительством радикального варианта судьбы кабинетского землевладения. Земли и доходы Кабинета были объявлены собственностью государства. Но постановление Временного правительства оказалось малопродуманным. Оно не разъясняло юридических основ этой передачи, порядка пользования земель для населения региона. В Алтайском округе постановление Временного правительства привело к развалу единого комплекса кабинетских земель. Ликвидация кабинетской собственности в регионе только усилила сопротивление местных чиновников Кабинета и радикальные настроения населения в отношении бывшей собственности императора.

Е.В. Демчик проанализировала деятельность Временного правительства по вопросу о земельной собственности свергнутого императора. П.А. Афанасьев раскрыл региональный контекст проблемы и значение для него принятого правительственного решения.

Ключевые слова: Февральская революция, Кабинет Его Императорского Величества, Временное правительство, кабинетское землевладение, Алтайский округ.

Цитирование. Афанасьев П. А., Демчик Е. В. Февральская революция 1917 года и земельная собственность российского монарха: общегосударственное измерение и региональный фактор // Вестник Волгоградского государственного университета. Серия 4, История. Регионоведение. Международные отношения. 2017. - T. 22, № 6. - C. 77-86. - DOI: https://doi.org/10.15688/jvolsu4.2017.6.8

Отречение Николая II в ходе Февральской революции 1917 г. и последовавшая ликвидация института монархии в России ознаменовали для страны начало новой государственности. Политическая сторона процесса падения монархии в силу исторической значимости всегда привлекала историков, и на сегодняшний день она получила достаточно полное и всестороннее освещение. Гораздо меньше внимание исследователей сосредоточивалось на владельческо-собственнических аспектах ликвидации российского самодержавия, связанных, в том числе, с важнейшей частью имущества бывшего императора - землями и управлявшими ими структурами Кабинета Его Императорского Величества, входившего в Министерство императорского двора. К началу 1917 г. кабинетское землевладение было представлено 2 крупными округами: Алтайским в Западной Сибири и Нерчинским в Восточном Забайкалье. Доходы от эксплуатации природных ресурсов этих регионов являлись одним из источников финансирования монархии. Поэтому падение самодержавия неизбежно затрагивало проблему земельной собственности отрекшегося царя.

Одно из единичных обращений к судьбе императорской собственности в целом после Февральской революции предпринято И.В. Зиминым. Из всех объектов собственности подробно рассматривая лишь состояние капиталов императорской семьи, автор на их примере раскрывает взаимосвязь владельческих аспектов и политического значения проблемы «бывшего царя» в ходе революционного процесса [9, с. 471-566]. Ликвидация землевладения свергнутого императора в большей степени вызывает интерес у региональных исследователей. На несколько десятилетий основополагающим стало обращение к этой проблеме в монографии Г.П. Жидкова. Автор рассматривал ликвидацию кабинетского землевладения с позиции интересов крестьян, проживавших в Алтайском и Нерчинском ок- 
ругах и притесняемых политикой Кабинета в предреволюционное десятилетие. Поэтому ликвидация земельной собственности императора в его округах привела к массовому движению населения против региональных чиновников Кабинета и проводимой ими хозяйственной политики [6, с. 238-256]. Н.Ф. Иванцова подробно рассмотрела положение бывших кабинетских земель Алтайского округа в процессе развития революционных событий 1917-1918 гг., не заостряя внимания на ликвидации этой формы собственности [10]. Публикации Е.С. Полякова характеризуют ситуацию, возникшую в Управлении Алтайского округа после ликвидации кабинетского землевладения, не касаясь ее причин и особенностей $[13 ; 14]$. В целом в исследовательской литературе ликвидация земельной собственности свергнутого императора рассматривается достаточно упрощенно, что можно объяснить вполне предсказуемым ее результатом - передачей этих земель государству. Между тем анализ деятельности правительственных структур по этому вопросу, дополненный обращением к региональным особенностям Февральской революции в крупнейшем владении императора - Алтайском округе, позволит выявить и оценить мотивы, факторы и событийную сторону процесса ликвидации землевладения российского самодержца.

К началу 1917 г. крупнейшим объектом в структуре землевладения российского императора был Алтайский округ площадью свыше 41 млн десятин. Эксплуатация природных богатств в этом регионе с середины XVIII в. являлась одним из источников дохода для Кабинета Его Императорского Величества. Такое значение Алтайского округа для финансирования российской монархии еще более закрепилось после 1906 г., когда Основные законы Российской империи зафиксировали неизменным ежегодный отпуск денег из казны Министерству императорского двора в размере 16359595 рублей. Недостающие суммы Министерство должно было зарабатывать самостоятельно, увеличивая доходность своих подразделений [2, с. 88-89].

По официальным данным наибольшую долю (почти $20 \%$ ) в собственных доходах Министерства императорского двора давал именно Алтайский округ. В 1906 г. он принес 2,5 млн рублей [6, с. 91; 11, с. 87]. Проводившаяся в регионе с 1907 г. интенсификация хозяйственной политики была направлена на стабилизацию этого дохода, получаемого главным образом от лесного и земельного хозяйства. Через 10 лет, в 1916 г., управляющий Кабинетом генерал Е.Н. Волков весьма позитивно оценил результаты этого хозяйственного курса, отметив, что «все прежние указания его выполнены» [7, л. 15]. С 1912 г. ежегодная общая прибыль по Алтайскому округу превышала 3,5 млн руб. [11, с. 87], а дальнейшие хозяйственные мероприятия в регионе проектировались «в целях увеличения доходности округа и рационального использования вверенного ему кабинетского имущества» [7, л. 16].

Обратной стороной этого позитивного для Кабинета развития являлась его жесткая политика по отношению к населению. В 1910-е гг. она вызывала общественную критику с трибуны Государственной думы и в периодических изданиях, что доставило немало сложностей Кабинету [3]. В годы Первой мировой войны Кабинет также неохотно шел на помощь местному населению, продолжая прежнюю хозяйственную политику [4]. В целом в предреволюционное десятилетие кабинетское ведомство в отстаивании земельнофинансовых интересов императора, как правило, оказывалось сильнее государственных структур, вынужденных в итоге считаться с требованиями Кабинета в отношении монаршего землевладения. Поэтому к началу 1917 г. землевладение и хозяйственная политика Кабинета вряд ли обладали полной поддержкой в государственных структурах из-за противоречий с интересами государства, что дополнялось далеко не однозначным отношением со стороны местного населения.

Вполне объяснимо, что после политического свержения самодержавия в ходе Февральской революции Временноеправительство не могло оставить без внимания землевладение Кабинета как существенную часть «наследия» императора. Уже на первом заседании вновь созданного правительства, состоявшегося 2 марта, по инициативе министра финансов М.И. Терещенко был поднят вопрос об охране всех земель императорской фами- 
лии - дворцовых, кабинетских и удельных путем установления надзора над ними одного комиссара, подчиненного министру финансов [8, с. 386]. Очевидно, здесь имелась в виду юридическая защита земель, предотвращавшая любые посягательства на нее. Примечательно, что это предложение никак не касалось вопроса о собственности всех перечисленных категорий земель, существенно отличавшихся по своему юридическому статусу. Причина такой быстрой постановки вопроса об императорском землевладении, скорее всего, была связана с главным политическим вопросом, рассмотренным на этом же заседании, - «о дальнейшей судьбе членов бывшей императорской фамилии», посвященным обеспечению их безопасности. Хотя предположение министра финансов было сразу же одобрено, но никаких сведений о его исполнении обнаружить не удалось.

Представленное решение свидетельствовало, что четкой позиции по вопросу о земельной собственности свергнутого императора у нового правительства еще не существовало, но имелось лишь понятие о значимости этой проблемы. При этом Временное правительство оказывалось в непростой правовой ситуации. С одной стороны, дворцовые, удельные и кабинетские земли разделялись юридически в зависимости от их принадлежности разным членам рода Романовых. С другой стороны, как утверждает И.В. Зимин, новая власть не преследовала конфискационных целей по отношению к личному имуществу членов семьи Николая II, но это требовало четкого определения размытой границы государственной и личной собственности Романовых [9, с. 493].

Актуальным этот правовой вопрос являлся для кабинетских земель Алтайского и Нерчинского округов. Еще до революции в бюрократической среде в связи с подготовкой освободительной реформы 1861 г. и землеустройства в округах в конце XIX - начале $\mathrm{XX}$ в. поднимался вопрос о юридическом статусе кабинетского землевладения. Было признано их отличие от уделов и принципиальная разница с государственными землями. Чиновники склонялись к тому, чтобы считать кабинетские земли особым видом частной собственности, принадлежащей правящему императору [12, л. 4-4 об., 19 об.]. В то же время в практике делопроизводства нередко кабинетские земли назывались личной собственностью, вотчиной императора. Взаимосвязанным с правовым статусом кабинетского землевладения был вопрос о поступавших с них доходах. Они шли в бюджет Министерства императорского двора, откуда большая часть тратилась на нужды монархии как государственного института $[6$, c. 92-94]. Поэтому рассматривать доходы кабинетского землевладения «личным карманом» императора было бы неверно. Являясь вторым после финансирования из казны источником обеспечения бюджета министерства, кабинетские земли этой своей задачей явно выделялись из категории личных земель. Со всеми этими правовыми сложностями теперь предстояло столкнуться Временному правительству в решении судьбы кабинетских земель.

Новое обращение к собственности свергнутого императора Временное правительство предприняло на заседании 4 марта. Предшествовавшее представление министра финансов теперь получило иное направление. По его же представлению в ведение Министерства финансов был передан Кабинет Его Величества с назначением в него комиссара И.В. Титова [8, с. 27]. Формально это решение было гораздо шире предложения, принятого 2 марта, поскольку Кабинет распоряжался всеми финансово-хозяйственными делами Министерства императорского двора. Решение, безусловно, устанавливало контроль государства над всем финансированием бывшего императора, но при этом оно никак не проясняло положение земельной собственности, находившейся в управлении Кабинета. Только в заседании Временного правительства 7 марта вопрос о землях бывшего императора был заявлен как самостоятельная проблема. Министр земледелия А.И. Шингарев сообщил о необходимости установить порядок заведования и использования земель Кабинета [8, с. 46]. Возложив в ответ разработку этого вопроса на министров земледелия и финансов, правительство тем самым подтверждало отсутствие у него какихлибо четких представлений о дальнейшей судьбе землевладения императора.

Но уже через 3 дня в заседании 10 марта вновь был косвенно затронут вопрос о зе- 
мельной собственности Романовых. Предложения уже исходили от министра-председателя Г.Е. Львова. По его представлению было сохранено Главное управление уделов, ведавшее землями императорской фамилии, с оставлением на посту его руководителя В.С. Кочубея без назначения комиссара от правительства. Также полностью сохранялся и Кабинет. В контексте принятых ранее решений это, очевидно, должно было свидетельствовать об отсутствии у правительства каких-либо радикальных планов относительно земельной собственности императора и семьи Романовых. Косвенно об этом может говорить указание, данное тут же Кабинету, «на необходимость льготного отношения к крестьянам» [8, с. 67]. В русле дореволюционной хозяйственной политики Кабинета данное поручение было направлено на смягчение противоречий на местах. Контекст этого указания прямо говорил, что никакого коренного пересмотра в кабинетском землевладении правительство предпринимать не собирается. В определенной степени принятое предложение князя Г.Е. Львова проясняло запрос министра земледелия о главных принципах управления и использования земель Кабинета, демонстрируя со всей очевидностью, что правительство не склонно к радикальному решению вопроса о земельной собственности свергнутого императора.

На фоне отсутствия четко выраженной правительственной позиции о судьбе кабинетского землевладения ситуация в самом Алтайском округе складывалась поначалу независимо от центра. Развитие революционных событий в регионе началось 3-4 марта 1917 г. после получения и опубликования известий о свержении самодержавия. Главное управление Алтайского округа, не имея связи с Кабинетом и руководящих указаний от него, поначалу заняло выжидательную позицию к создаваемым на местах комитетам общественного порядка. Лишь получив 7 марта первую телеграмму из Петрограда о подчинении Министерства императорского двора Временному правительству и сохранении без изменений всех местных учреждений ведомства, руководство Алтайского округа стало конкретными шагами закреплять формальное сохранение своих полномочий в регионе [1, с. 29-30].
Ввиду неясности судьбы кабинетских земель Главное управление Алтайского округа на подведомственной территории пыталось максимально полно сохранить сложившуюся хозяйственную практику, отказываясь от каких-либо радикальных решений и допуская лишь разумный компромисс с новыми органами местной власти и требованиями населения [1, с. 30-33]. Такая позиция, по-видимому, не устроила Барнаульский комитет общественного порядка, претендовавший на полноту власти в регионе. Поэтому по своей инициативе 9 марта этот орган отправил телеграмму министру-председателю, министру земледелия и министру юстиции с требованием скорейшего решения вопроса о «громадном многомиллионном состоянии Алтайского округа, состоящего из земель, лесов, богатых земельных недр, заводов, домов» в целях обеспечения порядка и спокойствия в регионе. Особо авторы телеграммы отметили «громадную отрицательную роль, которую до сих пор Кабинет играл в жизни нашего Алтайского края» $[16$, л. 9], рассчитывая этим повлиять на решение правительства.

Телеграмма Барнаульского комитета актуализировала перед Временным правительством в решении вопроса о кабинетском землевладении мощный фактор, широко применявшийся с первых дней Февральской революции, - давление со стороны масс. Как показывает И.В. Зимин, оно имело место и по отношению к собственности Романовых. Если в Петрограде военные караулы отказывались охранять великокняжеские дворцы, требуя признать их собственностью государства [9, c. 498-499], то в Алтайском округе объектом притязаний населения стали, главным образом, леса Кабинета. Помощник начальника округа Л.Л. Маслов, сообщая в Кабинет о ситуации в регионе, писал, что в округе с первых дней революции наблюдалось «открытое выражение желаний раздела всего кабинетского имущества и смелые выступления против администрации округа» [5, с. 30]. Первые сообщения о самовольных порубках, прекращениях продажи леса и увольнении лесной стражи поступили в Управление округа 4 и 5 марта [15, л. 69 об.]. В Алтайском округе началось движение против кабинетских чиновников, которых население смещало с должно- 


\section{ОТЕЧЕСТВЕННАЯ ИСТОРИЯ}

стей лесничих, разоружало, выдворяло в другие селения. С конца первой декады подобные проявления активности населения лишь усилились $[10$, с. 61-62]. Этому способствовала не только революционная эйфория, но и предшествовавшая хозяйственная политика Кабинета наряду со свержением верховного собственника алтайских земель. Поэтому телеграмма Барнаульского комитета общественного порядка, вызванная ростом конфронтации населения с местными кабинетскими чиновниками, в концентрированной форме выразила давление населения Алтая на Временное правительство в скорейшем решении судьбы кабинетского землевладения.

Требование, полученное из Алтайского округа, заставляло правительство не только ускорить выработку решения о кабинетских землях, но и вынуждало принять к руководству уже фактически осуществлявшийся населением радикальный вариант захвата и распоряжения лесами и землями округа. Но правительство в лице Г.Е. Львова, по-видимому, сомневалось в таком решении, чем и можно объяснить последовавшую 10 марта рекомендацию Кабинету «льготного отношения к крестьянам». Однако уже 12 марта на заседании Временного правительства было рассмотрено представление министра земледелия А.И. Шингарева о кабинетских землях. Изучив размеры кабинетских земель и отнеся их к частной собственности императора, он «ввиду отречения Николая ІІ» предложил осуществить передачу всего землевладения Кабинета в собственность государства $[16$, л. 17 , 19 об.]. Также полностью прекращалось финансирование Кабинета из государственной казны, в которую теперь передавались и все доходы Кабинета. Радикальное решение вопроса о кабинетском землевладении сопровождалось узаконением передела кабинетской собственности. Все земельные, лесные, горнопромышленные объекты Кабинета подлежали распределению между двумя министерствами. Министерство земледелия принимало заведование лесными и земельными угодьями. В ведение министерства торговли и промышленности передавались недра и предприятия по их разработке на бывших землях Кабинета. До окончания разграничения предусматривалось сохранение существовавших управленческих структур Кабинета и их чиновников [8, с. 84]. Таким образом, представленные министром земледелия основания предусматривали фактическую ликвидацию Кабинета и его землевладения как самостоятельной автономной структуры.

Принятое решение о готовящейся в ближайшем будущем передаче землевладения и имущества Кабинета государству 13 марта было сообщено в Алтайский округ [16, л. 11]. Для Барнаульского комитета общественного порядка это решение, видимо, представлялось закономерным ответом на отправленную ранее телеграмму в связи со складывающейся в округе ситуацией. Однако для местных чиновников Кабинета данное сообщение означало потерю контроля над ситуацией в регионе и неясность перспектив своей службы.

Для согласования и рассмотрения предложения о передаче всех имуществ Кабинета в казну Временное правительство 12 марта создало комиссию при Министерстве земледелия [8, с. 84; 16, л. 47]. Совещание, рассматривавшее передачу кабинетских земель, состоялось 24 марта [16, л. 44]. По всей видимости, оно не внесло никаких принципиальных и существенных новшеств в проект министра земледелия. Очевидно, в этом не было необходимости, поскольку еще до официального объявления принятого решения, 20 марта, Временное правительство объявило все имущество Министерства двора перешедшим в собственность государства и состоящим под его охраной [8, с. 139]. Это решение, косвенно касавшееся и кабинетского ведомства, стало одним из первых публичных заявлений о судьбе царской собственности и было направлено на успокоение населения и предотвращение дальнейшего растаскивания того, что принадлежало ведомству императора.

Переход кабинетской собственности в государство окончательно был утвержден на заседании Временного правительства 27 марта 1917 года [17, с. 656]. Принятое постановление полностью повторяло представленные ранее министром земледелия правила. Теперь официально все кабинетские земли передавались в собственность государства. Постановление, однако, никак не разьясняло юридических основ данной передачи, не учитывало колебания дореволюционных чиновников Каби- 
нета относительно природы и статуса кабинетских земель. Очевидно, в условиях новой государственности, реального положения на местах и ожиданий местного населения подобное решение вопроса о бывшей императорской земельной собственности предполагалось не подлежащим никаким сомнениям. Вместе с тем принятое постановление никак не объясняло порядок пользования для населения вновь ставших государственными земель, в том числе возможной их аренды, пользования и т. п.

Постановление от 27 марта 1917 г., принятое без достаточного обсуждения, вряд ли являлось глубоко продуманным мероприятием. Нерешительность Временного правительства в первые дни работы в отношении земельной собственности императора натолкнулась на радикальные настроения населения. Поэтому можно считать, что принятое 12 марта и официально утвержденное 27 марта решение о кабинетском землевладении в определенной степени было результатом давления со стороны населения Алтайского округа. Для Временного правительства принятое постановление было лишь направлено на скорейшее решение одного из многих вопросов, связанных со свергнутым царем.

В конечном итоге передача земель Кабинета в казну оказалась удобной для правительства. Постановление о землях Кабинета в какой-то степени развязывало руки Временному правительству во многих вопросах, связанных с царем. Передача кабинетских земель в собственность государства разом прекращала любые споры и сомнения относительно их юридического статуса и возможности их учета как личных владений императора. Ликвидация кабинетского землевладения сразу же создавала правовое основание для лишения финансирования бывшего императора и его семьи. В дальнейшем при решении вопросов финансирования семьи Романовых лишь подтверждалось, что земли как источник доходов для бывшего императора больше не существуют [9, с. 497-498]. Изъятие кабинетской собственности в государство позволяло без каких-либо юридических тонкостей подобным же образом объявить собственностью государства все крупные объекты бывшего Министерства двора, а чуть позже и удельно- го ведомства [8, с. 289-290]. Поэтому постановление от 27 марта 1917 г. в какой-то степени можно считать ключевым в политике Временного правительства по отношению к владельческим вопросам бывшей императорской фамилии.

Для столичных властей решение вопроса о кабинетском землевладении переводило эту проблему в разряд неактуальных. Для местных структур бывшего Кабинета постановление Временного правительства только открывало сложный период приспособления и преобразования своей работы к новым условиям [18, л. 5-5 об.]. Ликвидация единого комплекса кабинетских земель в Алтайском округе привела к развалу ранее созданного хозяйственно-территориального комплекса и сопротивлению бывших кабинетских чинов этому процессу [13]. Однако положение в регионе теперь зависело не столько от правового статуса бывшего императорского землевладения, но в большей степени от радикализации настроений населения, многовластия на местах и углубления революционного процесса.

\section{ПРИМЕЧАНИЕ}

${ }^{1}$ Публикация подготовлена при совместной финансовой поддержке РФФИ и Министерства образования и науки Алтайского края в рамках реализации проекта «Историческое развитие Алтая в контексте общегосударственных и региональных процессов XVIII - начала XXI в.» (грант № 17-11-22006).

\section{СПИСОК ЛИТЕРАТУРЫ}

1. Афанасьев, П. А. Деятельность Управления Алтайского округа в региональном контексте Февральской революции / П. А. Афанасьев, А. А. Калашников // Известия Алтайского государственного университета. Серия «Исторические науки и археология». - 2017. - № 2 (94). - C. 28-35. - DOI: 10.14258/izvasu(2017)2-03.

2. Афанасьев, П. А. «Новый курс» хозяйственной политики Кабинета в Алтайском округе в начале XX в.: факторы и этапы развития / П. А. Афанасьев // Экономическая история Сибири XX - начала XXI в. - Барнаул : АКИПКРО, 2012. - Т. I. C. $87-95$.

3. Афанасьев, П. А. Противодействие «новому курсу» земельной политики Кабинета Его Им- 
ператорского Величества в Алтайском округе в начале 1910-х годов / П. А. Афанасьев // Исторический ежегодник. 2013. - Новосибирск : Параллель, 2013. - C. 44-60.

4. Афанасьев, П. А. Руководство Кабинета Е.И.В. хозяйством Алтайского округа в годы Первой мировой войны / П. А. Афанасьев // Экономическая история Сибири XX - начала XXI века. Барнаул : МЦ ЭОР, 2015. - Т. 1. - С. 230-237.

5. Борьба трудящихся за установление Советской власти на Алтае (1917-1920 гг.) : сб. документов. - Барнаул : Алтайское кн. изд-во, 1957. - 504 с.

6. Жидков, Г. П. Кабинетское землевладение (1747-1917 гг.) / Г. П. Жидков. - Новосибирск : Наука, 1973. - 264 с.

7. Журнал совещания членов Кабинета и земельно-лесных чинов об учете земель округа, об упорядочении ведения хозяйства // Государственный архив Алтайского края (ГААК). - Ф. 4. - Оп. 1. Д. $454 .-17$ л.

8. Журналы заседаний Временного правительства, март - октябрь 1917 г. В 4 т. Т. 1. Март апрель 1917 г. - М. : РОССПЭН, 2001. - 447 с.

9. Зимин, И. В. Царские деньги. Доходы и расходы Дома Романовых: повседневная жизнь Российского императорского двора / И. В. Зимин. М. : Центрполиграф, 2011. -686 с.

10. Иванцова, Н. Ф. Сибирское крестьянство в 1917 - начале 1918 г. / Н. Ф. Иванцова. - М. : Прометей, 1990. - 167 с.

11. Обзор деятельности Кабинета его императорского величества за 1906-1915 годы. - Пг. : Тип. Главного управления уделов, 1916. - 111 с.

12. О юридическом значении Алтайского округа // Российский государственный исторический архив (РГИА). - Ф. 468. - Оп. 24. - Д. 429. - 52 л.

13. Поляков, С. Е. Взаимодействие управления Алтайского округа с Алтайским губернским земельным комитетом (1917-1918 гг.) / С. Е. Поляков // Гуманитарные исследования на пороге нового тысячелетия. - Барнаул : Изд-во Алтайского гос. ун-та, 2001. - С. 34-36.

14. Поляков, С. Е. Реорганизация кабинетской системы управления на Алтае в 1917-1919 гг. / С. Е. Поляков // Актуальные вопросы истории Сибири. Третьи чтения памяти А.П. Бородавкина. - Барнаул : Изд-во Алтайского гос. ун-та, 2001. - С. 249-253.

15. Приказ начальника округа о подчинении Временному правительству; протокол совещания согласительной комиссии о мерах по обеспечению общественного порядка. Копии. Доклады начальника округа Кабинету о положении дел в лесничествах округа // ГААК. - Ф. 4. - Оп. 1. - Д. 540. 151 л.

16. Приказы по Министерству земледелия и торговли и промышленности (копии) и переписка с комиссаром Временного правительства и с управляющими переселенческим делом в областях Сибири о передаче в казну кабинетских земель // Государственный архив Российской Федерации. Ф. 1797. - Оп. 1. - Д. 227. - 451 л.

17. Собрание узаконений и распоряжений правительства. - 1917. - № 77. - Ст. 439.

18. Сообщение начальника Алтайского округа о переходе имуществ Кабинета его величества в собственность государства // РГИА. - Ф. 482. Оп. 10. - Д. 582. -6 л.

\section{REFERENCES}

1. Afanasyev P.A., Kalashnikov A.A. Deyatelnost Upravleniya Altayskogo okruga $\mathrm{V}$ regionalnom kontekste Fevralskoy revolyutsii [Activity of the Altai District Administration in the Regional Context of the February Revolution]. Izvestiya Altayskogo gosudarstvennogo universiteta. Seriya istoricheskie nauki $i$ arkheologiya [Science Journal of Altai State University. Historical Sciences and Archeology], 2017, no. 2, pp. 28-35. DOI: 10.14258/ izvasu(2017)2-03.

2. Afanasyev P.A. «Novyy kurs» khozyaystvennoy politiki Kabineta v Altayskom okruge v nachale XX v.: faktory i etapy razvitiya ['New Course' of Economic Policy of the Cabinet in the Altai District at the Beginning of the $20^{\text {th }}$ Century: Factors and Stages of Development]. Ekonomicheskaya istoriya Sibiri $X X-$ nachala XXI v. [Economic History of Siberia $\left(20^{\text {th }}-\right.$ Early $21^{\text {st }}$ Century)]. Barnaul, AKIPKRO Publ., 2012, vol. 1, pp. 87-95.

3. Afanasyev P.A. Protivodeystvie «novomu kursu» zemelnoy politiki Kabineta Ego Imperatorskogo Velichestva v Altayskom okruge v nachale 1910-kh godov [Counteraction to the 'New Course' of Land Policy of the Cabinet of His Emperial Majesty in the Altai District at the Beginning of the 1910s]. Istoricheskiy ezhegodnik. 2013 [History Annual. 2013]. Novosibirsk, Parallel Publ., 2013, pp. 44-60.

4. Afanasyev P.A. Rukovodstvo Kabineta E.I.V. khozyaystvom Altayskogo okruga $\mathrm{v}$ gody Pervoy mirovoy voyny [The Management of the Altai District's Economy by the Cabinet of His Emperial Majesty During the Years of World War I]. Ekonomicheskaya istoriya Sibiri XX - nachala $X X I$ veka [Economic History of Siberia of the $20^{\text {th }}-$ Beginning of the $21^{\text {st }}$ Century]. Barnaul, MC EOR Publ., 2015, vol. 1, pp. 230-237.

5. Borba trudyashchikhsya za ustanovlenie Sovetskoy vlasti na Altae (1917-1920 gg.): Sbornik dokumentov [Fight of Workers for Establishment of the Soviet Power in Altai (1917-1920): Collection ofDocuments]. Barnaul, Altayskoe knizhnoe izd-vo, 1957. 504 p. 
6. Zhidkov G.P. Kabinetskoe zemlevladenie (1747-1917 gg.) [The Cabinet's Land Tenure (17471917)]. Novosibirsk, Nauka Publ., 1973. 264 p.

7. Zhurnal soveshchaniya chlenov Kabineta i zemelno-lesnykh chinov ob uchete zemel okruga, ob uporyadochenii vedeniya khozyaystva [The Records of Meeting of Members of the Cabinet and Land-Forest Officials about Accounting of the District's Lands, about Economy Management]. Gosudarstvennyy arkhiv Altayskogo kraya [State Archive of the Altai District], F. 4, Op. 1, D. 454, 17 p.

8. Zhurnaly zasedaniy Vremennogo pravitelstva, mart-oktyabr 1917 g. V4 t. T. 1. Martaprel $1917 \mathrm{~g}$. [Records of Sessions of the Provisional Government, March - October 1917. In 4 vols. Vol. 1. March - April 1917]. Moscow, Rosspen Publ., 2001. $447 \mathrm{p}$.

9. Zimin I.V. Tsarskie dengi. Dokhody i raskhody Doma Romanovykh: povsednevnaya zhizn Rossiyskogo imperatorskogo dvora [Emperor's Money. Incomes and Expenses of the Romanovs' House: Everyday Life of the Russian Emperor Yard]. Moscow, Tsentrpoligraf Publ., 2011.686 p.

10. Ivantsova N.F. Sibirskoe krestyanstvo $v$ 1917 - nachale 1918 gg. [The Siberian Peasantry in 1917 - the Beginning of 1918]. Moscow, Prometey Publ., 1990. $167 \mathrm{p}$.

11. Obzor deyatelnosti Kabineta ego imperatorskogo velichestva za 1906-1915 gody [Overview of Activities of the Cabinet of His Emperial Majesty for 1906-1915]. Petrograd, Tip. Glavnogo upravleniya udelov, 1916. $111 \mathrm{p}$.

12. O yuridicheskom znachenii Altayskogo okruga [Documents on Legal Value of the Altai District]. Rossiyskiy gosudarstvennyy istoricheskiy arkhiv [Russian State Historical Archive], F. 468, Op. 24, D. 429, 52 p.

13. Polyakov S.E. Vzaimodeystvie upravleniya Altayskogo okruga s Altayskim gubernskim zemelnym komitetom (1917-1918 gg.) [Interaction of the Altai District Administration with the Altai Provincial Land Committee (1917-1918)]. Gumanitarnye issledovaniya na poroge novogo tysyacheletiya [Humanities Research at the Turn of the New Millennium]. Barnaul, Izd-vo Altayskogo gos. un-ta, 2001, pp. 34-36.
14. Polyakov S.E. Reorganizatsiya kabinetskoy sistemy upravleniya na Altae v 1917-1919 gg. [Reorganization of the Cabinet's System of Management in Altai in 1917-1919]. Aktualnye voprosy istorii Sibiri. Tretyi chteniya pamyati A.P. Borodavkina [Topical Issues of History of Siberia. Third Readings in Memory of A.P. Borodavkin]. Barnaul, Izd-vo Altayskogo gos. un-ta, 2001, pp. 249-253.

15. Prikaz nachalnika okruga o podchinenii Vremennomu pravitelstvu; protokol soveshchaniya soglasitelnoy komissii o merakh po obespecheniyu obshchestvennogo poryadka. Kopii. Doklady nachalnika okruga Kabinetu o polozhenii del v lesnichestvakh okruga [Order of the Chief of the Altai District on Subordination to Provisional Government; Protocol of the Meeting of Conciliation Commission on the Measures for Public Order Support. Reports of the District's Chief to the Cabinet about the Situation in Forest Areas of the Altai District]. Gosudarstvennyy arkhiv Altayskogo kraya [State Archive of the Altai District], F. 4, Op. 1, D. 540, 151 p.

16. Prikazy po Ministerstvu zemledeliya i torgovli i promyshlennosti (kopii) i perepiska s komissarom Vremennogo pravitelstva i s upravlyayushchimi pereselencheskim delom v oblastyakh Sibiri o peredache $v$ kaznu kabinetskikh zemel [Orders of the Ministry of Agriculture, Trade and Industry (Copies) and the Correspondence with the Commissioner of Provisional Government and with the Supervisors of Resettlement Affair in the Areas of Siberia, on Transfer of the Cabinet's Lands to Treasury]. Gosudarstvennyy arkhiv Rossiyskoy Federatsii [State Archive of the Russian Federation], F. 1797, Op. 1, D. 227. 451 p.

17. Sobranie uzakoneniy i rasporyazheniy pravitelstva [Collection of Legislative Enactments and Orders of the Government], 1917, no. 77, art. 439.

18. Soobshchenie nachalnika Altayskogo okruga o perekhode imushchestv Kabineta ego velichestva $\mathrm{v}$ sobstvennost gosudarstva [Message of the Chief of the Altai District about Transfer of Property of the Cabinet of His Majesty to the Property of the State]. Rossiyskiy gosudarstvennyy istoricheskiy arkhiv [Russian State Historical Archive], F. 482, Op. 10, D. 582,6 p.

\section{Information about the Authors}

Pavel A. Afanasyev, Candidate of Sciences (History), Associate Professor, Altai State Pedagogical University, Molodezhnaya St., 55, 656031 Barnaul, Russian Federation, pavel_afanasev@mail.ru, https://orcid.org/0000-0001-7672-8012

Evgeniya V. Demchik, Doctor of Sciences (History), Professor, Head of Department of National History, Dean of Faculty of History, Altai State University, Prosp. Lenina, 61a, 656049 Barnaul, Russian Federation, demtchikev@mail.ru, https://orcid.org/0000-0002-6218-447X 


\section{ОТЕЧЕСТВЕННАЯ ИСТОРИЯ}

\section{Информация об авторах}

Павел Алексеевич Афанасьев, кандидат исторических наук, доцент, Алтайский государственный педагогический университет, ул. Молодежная, 55, 656031 г. Барнаул, Российская Федерация, pavel_afanasev@mail.ru, https://orcid.org/0000-0001-7672-8012

Евгения Валентиновна Демчик, доктор исторических наук, профессор, заведующая кафедрой отечественной истории, декан исторического факультета, Алтайский государственный университет, просп. Ленина, 61a, 656049 г. Барнаул, Российская Федерация, demtchikev@mail.ru, https://orcid.org/0000-0002-6218-447X 